\title{
Herminio Barreiro, o socialrealismo e temas afíns: o gran pioneiro
}

\author{
Xesús ALONSO MONTERO
}

Releo, unha vez máis, o seu artigo "Galleguismo y realismo" e, de novo, non saio do meu asombro. Publicouno en La Noche, de Santiago, 017 de agosto de 1963, tempo pouco propicio para que se fixesen na prensa diaria afirmacións coma esta:

Y es... de idealistas pretender gigantescas unificaciones o secesiones separatistas trasnochadas que lo único que harán sería dificultar el proceso revolucionario de los pueblos.

Hai outras afirmacións: repárese nesta:

El federacionismo sólo es posible en un país políticamente unificado, pero unificado de verdad y no de modo ficticio y propagandístico. Una vez realizado el proceso revolucionario en todo el territorio, mirando con buena lógica y sin otra alternativa dialéctica al progreso del mismo, es inevitable la autonomización para hacer realmente efectivo este progreso. El ejemplo lo tenemos en muchos países socialistas. Hay repúblicas en la URSS que, durante la dominación zarista, veían desaparecer día a día su lengua y su cultura propias. Pues bien, uno de los últimos premios Lenin de Literatura fue ganado por un escritor de una de esas repúblicas que ya habían perdido por completo el cultivo de su lengua escrita. La obra se publicó simultáneamente en su idioma original y en ruso, siendo luego traducida a varios idiomas más de los que se hablan en la URSS.

O autor de "Galleguismo y realismo", un universitario de 26 anos, non só escribe como un marxista senón que manifesta a súa admiración á organización territorial da Unión Soviética e ós principios que a inspiraban. No ano 1963, en efecto, xa había universitarios (licenciados ou non) que pensaban deste xeito, algúns dos cales escribían (con pseudónimo) en termos semellantes en revistas clandestinas. $O$ insólito é que textos como os dous transcritos se publiquen, nun periódico normal e legal de provincias, no ano 1963, cando o zar do Ministerio de Información se chamaba Manuel Fraga Iribarne, ministro tamén caracterizado polas súas teimas antimarxistas. ¡Aínda hoxe asombra! Hai que supoñer que Herminio Barreiro contaba no periódico coa simpatía de Borobó, antifranquista (non comunista) que acollía a cotío páxinas un pouco ousadas, especialmente se versaban sobre asuntos literarios.

De asuntos literarios (e lingüísticos) trata "Galleguismo y realismo", sen omitir algunha cuestión política como cando afirma que

El galleguismo, tal y como se ha venido desarrolando y se desarrolla aún hoy desde, aproximadamente, principios de siglo, es un concepto federacionista e integracionista falso. 
El de hoy es ya supertrasnochado. Obedece a unos intereses de clase y no es progresivo ni refleja las verdaderas y más apremiantes necesidades del pueblo gallego.

Herminio non só fala de política senón que o fai con terminoloxía marxista ("intereses de clase", "necesidades del pueblo gallego") o que, sen dúbida, preocupou a Borobó, que, pese a todo, publicou o artigo. Xa aquí, apunta á actividade intelectual do grupo que, daquela, protagonizaba o discurso cultural do galeguismo: a editorial Galaxia. Denúnciao con esta contundencia:

Ha quedado reducido a un grupo de intelectuales al estilo que ya podemos llamar muy bien tradicional y conservador [...] Beben en la ideología de un Jaspers, por ejemplo, que, con Heidegger y compañía se convertirían, andando el tiempo — ¡lo que son las cosas!— en cómplices confesos del nazismo.

Segue a referirse a Galaxia cando se centra máis na literatura:

Estos llamados galleguistas constituyen hoy, ahora, a nuestro lado, un círculo cerrado... y no quieren ni oír hablar de compromiso [...].

Pretender, por tanto, que trabaja por su tierra y por sus hombres, por la sociedad en que vive y a la que se debe plenamente, el señor que nos habla de extrañas cuevas demoníacas, de la patología del hambre (esto, claro, sólo puede leerse con cierta tranquilidad cuando se tiene la panza repleta) o de los ensueños que produce el vino albariño en un atardecer de Cambados, es exhibir el cinismo y el esteticismo más repugnante en la misma cara de la miseria.

O escritor das covas era Daniel Cortezón, autor d'As covas do Rei Cintolo; o da patoloxía da fame era Domingo García-Sabell, autor dun ensaio co que a esquerda foi moi reticente por pouco sociolóxico, e o dos efluvios líricos producidos polo albariño era Álvaro Cunqueiro e, quizais, José María Castroviejo, compañeiro de viaxe en moitas xornadas literarias de tema gastronómico ou báquico.

Herminio, desde o seu marxismo e desde o seu compromiso (sen dúbida sartreano), reprocha ó grupo de Galaxia, hexemónico daquela no mapa literario de Galicia, a súa entrega a un tipo de literatura desvencellada da realidade, unhas páxinas que "deberán tener un pálpito profundo de vida, una sensación de rebeldía sin perder la calidad".

É o momento en que cita uns exemplos recentes: "Longa noite de pedra, de Celso Emilio Ferreiro, y ciertos poemas y cuentos de alguna publicación gallega en el extranjero". Quizais se refira a poemas de Luís Seoane e ás Memorias dun neno labrego, de Neira Vilas.

E xa aquí, Herminio debrúzase sobre a cuestión do idioma:

Y pretender que publicando libros para leerlos uno mismo se resuelve el problema de la conservación del idioma, es lo más pueril y mentecato que uno pueda imaginarse.

\section{$[\ldots]$}

No escribo estas notas en gallego porque sé que las leerá más gente si van en castellano. Con ello no quiero dar a entender que sea pesimista en cuanto al destino de nuestro idioma. 
Lo hago ahora así porque la circunstancia histórica presente así me lo exige, pero sé muy bien que nuestra lengua gallega será revitalizada, aunque tenga que ocupar un lugar secundario que las necesidades de las relaciones sociales reservan siempre a los idiomas minoritarios. El gallego sólo puede comenzar a revitalizarse con el silabario. Y para llegar al silabario hay que enfrentarse con el primer problema que se nos plantea: la España de hoy. Después sí que podermos hablar de alfabetización, cultura popular, etc.

A "questione della lingua", tal como Herminio entende os problemas do galego en 1963, está pouco explicitada, explicitación imposible, por outra parte, no espazo dun artigo periodístico, escrito, no seu caso, o dun cavilador marxista, con non pouca autocensura. De todos os xeitos non é prioritaria, nesa altura, a praxe idiomática en galego, unha lingua que "sólo puede comenzar a revitalizarse con el silabario". Nesta formulación tan sintética, Herminio Barreiro, que xa ía para pedagogo e historiador da educación, apunta —ou moito me trabuco- ó feito de que só cando o idioma galego sexa o idioma escolar desde o primeiro ensino (o "silabario") asistiremos a unha verdadeira revitalización. Herminio no parágrafo final do seu artigo volve a ser moi pouco explícito, pero cremos entendelo cando apunta que "hay que ir a Galicia por España y no al revés... somos hermanos de todos los pueblos peninsulares. Nuestros primeros objetivos son idénticos". Ou sexa, compre derrubar a Ditadura e instaurar a Democracia en España, e, xa nesta situación, o idioma galego deixará de esmorecer pois accederá a unha instancia de prestixio e eficacia moi importante: o silabario, o ensino primario.

Herminio, malia a censura franquista, finaliza o artigo cunha especie de chamamento formulado en termos moi propios do entusiasta marxismo que tiñan algúns mozos da época:

¿A qué viene, pues, este oscurantismo? [o dos intelectuais de Galaxia]. ¿Por qué ostentamos esta inoportuna tibieza de espíritu en un momento prerrevolucionario tan claro dialécticamente (a cursiva é miña) ¿A qué esperamos?

Penso que Herminio, doce anos antes da morte de Franco, era un optimista histórico, como outros mozos marxistas daqueles anos.

No que Herminio acerta totalmente é na caracterización e denuncia que fai da literatura galega proposta e exercitada polo grupo Galaxia: unha literatura allea ós postulados do compromiso sartreano. Feito o diagnóstico, Herminio propón un tipo de literatura que, sinalando as situacións inxustas, leve ó lector a unha toma de conciencia e a tomar partido.

Sobre esta cuestión concreta publiquei tres artigos algo anteriores, o primeiro en $E l$ Progreso (Lugo) e os outros dous en La Noche (Santiago): "Sobre literatura comprometida" (nov., 1961), "Tragedia en dos actos del escritor gallego" (7-3-1962) e "Parábola de las camisas y las corbatas" (3-3-1963). Dous meses despois, X.L. Méndez Ferrín lía un texto no Museo de Lugo titulado "As dúas caras da literatura galega", que é, entre outras cousas, un alegato contra Ramón Piñeiro, contra o Piñeiro para quen a nosa literatura é, no esencial, "o lirismo como expresión da saudade, e o humorismo e máis a pantasía como expresión da libertade". É neste ensaio (en parte aínda inédito) onde Méndez Ferrín, sen negar a veta teorizada por Piñeiro, pon o acento nos escritores que teñen un pé na luz do esprito 
creador e outro pé no áspero mundo das realidades toscas e inmediatas que cinguen ao home, mediatizan ao home, degradan ao home.

Os traballos indicados son algo anteriores ó de Herminio Barreiro, quen -cómpre resaltal— non só aborda o tema da literatura comprometida senón que toca cuestións que eu nin sequera menciono (a estrutura da URSS, o nazismo de Heidegger, o galego na escola, a situación prerrevolucionaria en España...). Por se fose pouco, Hermino emprega nalgúns parágrafos unha terminoloxía marxista, que, nos meus artigos, é menos visible.

De todos os xeitos, imponse aclarar que o debate sobre o compromiso literario, esbozado por min desde 1961 e por Herminio Barreiro en 1963, é un debate un pouco serodio. Noutras partes de España (Madrid, Cataluña...) a esquerda xa o iniciara bastantes anos antes. É certo que na Escolma de poesía galega: os contemporáneos, Fernández del Riego publica dúas autopoéticas nas que os autores (Luís Seoane e Celso Emilio Ferreiro) concordan coa "poesía comprometida". Isto é o que se propoñen dous poetas, pero, no universo da crítica e da erudición literarias, as primeiras páxinas comprometidas co compromiso son as indicadas no presente artigo, nomeadamente as de Herminio Barreiro, autor dun artigo que vai máis alá e que o converte no pioneiro maior da cuestión no acontecer literario da Galicia de Posguerra. 